\title{
FROM BOTH SIDES OF THE CLASSROOM: PERSPECTIVES ON TEACHER FEEDBACK ON ACADEMIC WRITING AND FEEDBACK PRACTICE
}

\author{
Alvin Ping Leong ${ }^{1 *}$, Hwee Hoon Lee ${ }^{2}$ \\ ${ }^{1}$ Nanyang Technological University, Singapore \\ ${ }^{2}$ Singapore Institute of Technology \\ *E-Mail: alvin.leong@ntu.edu.sg
}

\begin{abstract}
Research on feedback on student writing has investigated numerous aspects over the years. However, focused studies involving perspectives of both teachers and students in a particular educational setting are rare. This study investigated the views of teachers and students from a university in Singapore regarding feedback on academic writing and feedback practice. Nine experienced writing teachers and eight undergraduates participated in focus-group discussions in separate sessions. Discussions covered topics on the purpose of feedback and the specific areas that feedback should cover. Both teachers and students agreed that the purpose of feedback should be to help students become reflective and independent learners. The teachers tended to use feedback to justify the grades awarded to the assignments, and tailored their feedback to the requirements of the respective courses. The students, however, felt that the feedback needed to be more detailed. The individual needs of the students were also not always met. We propose recommendations to create a dialogic environment between teachers and students, and so facilitate the provision of personalized feedback on academic writing.
\end{abstract}

Key words: teacher feedback, feedback practice, perspectives, academic writing

\section{INTRODUCTION}

Academic writing teachers know that their feedback on student writing plays an essential role in influencing their students' learning. A common understanding of the purpose of feedback is that it narrows the gap between current understanding and performance, as seen from the learners' ability to achieve the set goals of assignments.

Over the years, research on teacher feedback has focused on the form, type and uptake of feedback, the circumstances affecting the effectiveness of feedback, the implementation of feedback, and the use of technology to enhance the feedback process (Bruno and Santos 2010, Ferris 2014, Glover et al. 2015, Hattie and Timperley 2007, Lee 2008, Stern and Solomon 2006). Most recently, attention has shifted towards the need to engage students in the feedback process. Dialogic feedback, including both teacherstudent and student-student interaction, is seen as a way forward in improving student response to feedback (Orsmond et al. 2013) and working towards sustainable feedback (Carless et al. 2011, Mutch et al. forthcoming, Nicol 2010a). This 'feedback as dialogue' 
model is based on constructivist principles. One key feature of this perspective is iteration, highlighted in Laurillard's (2002) framework, where the teacher-student dialogue (or co-operative activity) is described as being discursive, adaptive, interactive, and reflective. However, while feedback is perceived as communication - an opportunity for dialogue with and among students, and for self-regulation of learning - the usefulness and effectiveness of teacher feedback continue to be questioned (Pitt and Norton 2017, Price et al. 2010). For example, students have been reported to complain that feedback is not timely or that they are not always clear about the purpose of feedback, so that they are unable to utilize it to improve their work (Price et al. 2010, Weaver 2006).

Studies involving teachers on the effectiveness of feedback have examined how their beliefs about teaching and learning shape their feedback and influence feedback practice. It has been found that there is an apparent disconnect between reported and actual practice (Lee 2009, O’Donovan, Rust, and Price 2016). An example of this disjuncture, as reported by Lee (2009), is that language teachers tend to focus on grammatical accuracy in their feedback, although they believe that good writing is more about the development and organization of ideas. Another example is that teachers often provide corrective and direct feedback even though they believe that feedback should be indirect to help students locate and correct their own errors. While effective feedback in the form of coherent and cohesive texts is recommended (Mahboob 2015), teachers have also indicated various factors which impede their ability to provide timely and effective feedback. These factors include contextual constraints such as large class sizes, heavy teaching, and administrative loads, as well as a mismatch between learner attitude and teacher expectations (Lee, Leong, and Song 2017, Weaver 2006).

With the wealth of studies on teacher and student perceptions of feedback, what else can we learn about reinforcing students' learning through feedback? One area with little focus is how both teachers and students in the same educational setting view the current state of feedback practice. Studies in this area are few and far between. Hyland's (2013a, b) interviews with students and professors at a Hong Kong university is a notable and welcome exception. His study found a mismatch between what students expected and what professors typically provided. Whereas the students expected grammar correction in the feedback - possibly due to influence from their secondary-school education-the professors did not appear to place equal emphasis on language issues, preferring instead to focus on content. The professors also did not favor drafts, as writing was not always seen as a vehicle for learning. Other incongruities were also noted by Weaver (2006). The British undergraduates that she surveyed did not think feedback was as effective as it could be, especially if it was vague or did not relate to the assessment criteria.

More work certainly needs to be done in this area. Indeed, a collective understanding of the views of both students and teachers is crucial in addressing not merely the writing needs of students but any revisions to feedback practice among teachers. The aim of this study, therefore, was to determine the extent of match between teacher and student perspectives about teacher feedback on academic writing and feedback practice. We believe that when teachers identify potential gaps and try to achieve a match between their own perspectives and those of the learners, they would be able to generate feedback that is pertinent to their students' needs and preferences, and so help learners effectively utilize feedback to improve their writing. 


\section{Data Collection AND ANALYsis}

This project, based entirely on focus-group discussions, was approved by the Institutional Review Board of the first author's university. The focus-group format was adopted as it encouraged in-depth responses in an informal setting. The research team, comprising three members, first sent email invitations to two groups to participate in the study-one to all writing teachers at the language centre (hereafter, 'Centre') of the first author's university, and the other to humanities and social sciences students. These students were selected because the focus-group discussions revolved around samples of feedback on a written assignment that they had recently completed, so the feedback experience would be fresh in their minds. For this reason, students from other disciplines were excluded from the study.

At this point, a word about the setting of the study is necessary. The Centre offers core writing modules to three colleges: engineering, science, and the humanities and social sciences. English is the medium of instruction for all the Centre's courses. Modules on academic and professional English are offered by the Centre, including English proficiency, technical writing, research writing, and writing at the workplace. In all of the Centre's courses, continuous assessment is adopted, with summative, norm-referenced assessment being the standard. Depending on the nature of the module, assignments could be 300 words long (e.g., abstract writing) to 3,000 words long (e.g., report writing). On average, a writing class comprises 25 students. The majority of students enrolled at this university are Singaporeans with about 12 years of education with English as the medium of instruction.

Nine teachers and eight students responded to the invitation. The teachers had at least eight years of experience in teaching writing at the undergraduate level. The student respondents had attended at least one research-writing course offered by the Centre. All respondents were given three samples of written feedback on student essays as reference material for the focus-group discussions. The student essays were a critical evaluation of the introduction section of a research article. Having the same texts to base the discussions on turned out to be a good idea, as they provided a stepping stone to deeper discussions revolving around the respondents' experiences with either the giving or receiving of feedback.

Focus-group discussions were conducted separately for the teachers and students. Each focus group comprised three to four respondents, and lasted between 45 and 60 minutes. Each session, with the respondents' permission, was audio-recorded. All respondents were assured of confidentiality and anonymity. The interviews were completed within two months.

The interviews followed a semi-structured format. The questions asked related broadly to aspects of feedback such as form (symbols, abbreviations, short phrases, and longer comments), focus (content, structure, and language), purpose, and expectations of feedback. The two sets of interview data were later transcribed and analyzed. Analyses took place over two months. Following close reading of the transcripts, the research team identified recurring themes across both sets of data; these included "beliefs", "practice", "purpose", "time constraint", and "grade justification". Content analysis of the interview transcripts was performed using NVivo10 (version 10). Each transcript was collectively analyzed and coded by the research team. Interpretations were subjected to rigorous deliberation by the team, until a consensus was reached. 


\section{RESULTS AND DISCUSSION}

The issues raised in the focus-group discussions fall into three broad strands - the respondents spoke candidly about (a) the purpose of teacher feedback, (b) clarity of the feedback, and (c) the specific areas (e.g., language, rhetorical structure) the feedback should address. We begin with the purpose of feedback.

\subsection{Purpose of feedback}

The typical form of written teacher feedback resembles that illustrated in Figure 1. As evident from the sample, such feedback generally takes the form of underlined or circled words, symbols (e.g., question marks), and handwritten comments inserted in the margins and at the end of the assignment.

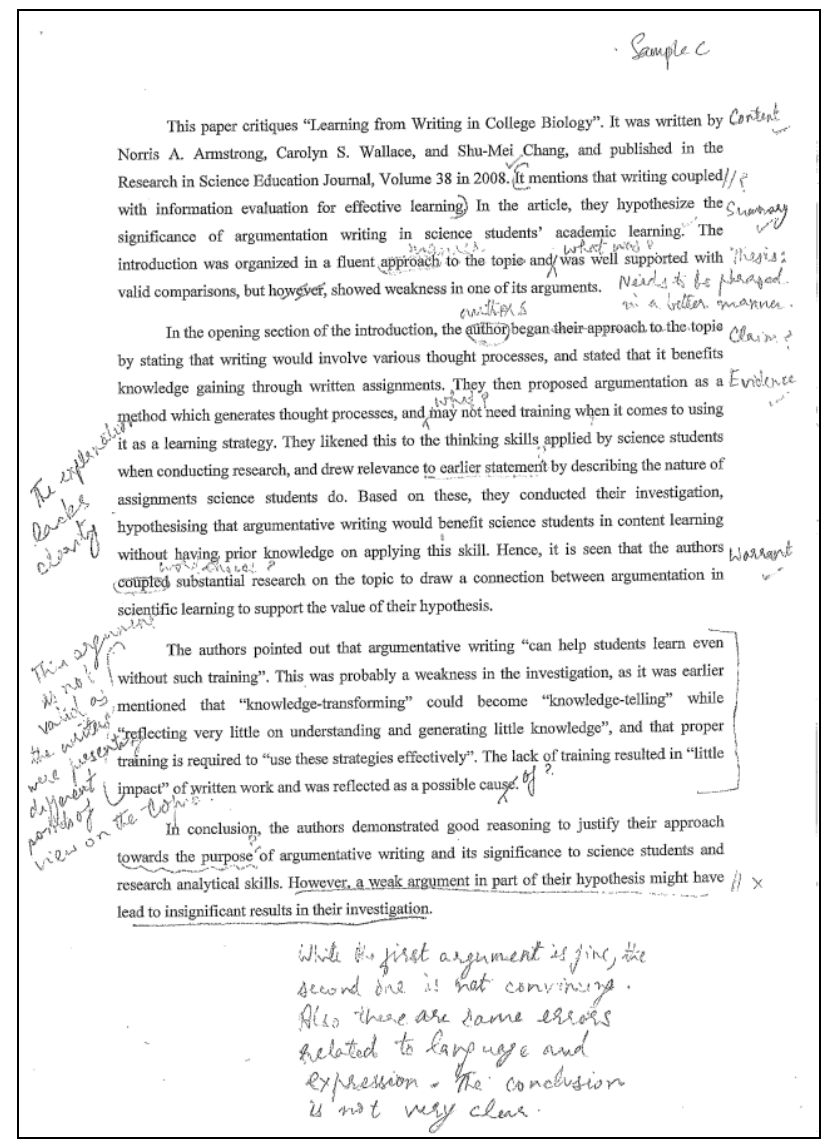

Fig. 1 Sample of typical teacher feedback

From the teachers' perspective, such feedback is generally guided by two factors-(a) their personal beliefs regarding their students' learning process, and (b) their students' focus on grade justification. The former relates to the broader philosophical view of the 
role of feedback in helping students better handle future similar tasks. The latter, on the other hand, is grounded in practical concerns, which may compromise the former to some extent. We take each factor in turn in the following sub-sections.

\subsubsection{Teachers' personal beliefs}

Without exception, the teachers laid emphasis on the learning process of their students, where the feedback provided was seen not as a product in itself but as a means to an end. There was consensus that the feedback should be constructive in nature. By this, they meant that the feedback should be geared towards helping students reflect on their respective areas of weaknesses and, more importantly, work out solutions for themselves. (In all cases below, teacher participants are assigned pseudonyms beginning with the letter "T", e.g., "Teresa", and student participants with the letter "S", e.g., "Samuel".)

My teaching philosophy is, I think, you know, students need to be independent, especially since they are in university. I like students who are resourceful. They go and find out things for themselves; they don't expect me to tell them everything. So even when I give them feedback, I don't tell them everything in detail, because I like them to reflect, and I like them to actually come back to ask me-you know, how do you mean by this, how do you think I can improve? (Teresa)

In consequence, their feedback was typically explicit but indirect, i.e., students were told explicitly what had gone wrong, but given adequate cues to find out more about the slip-e.g., "remember that lecture, or that tutorial", "refer to this website" (Tammy).

The literature suggests that the teachers' use of constructive feedback in this way plays an important role in facilitating the development of self-assessment (i.e., reflection) in learning. This has been identified by Nicol and Macfarlane-Dick $(2006,205)$ as an aspect of good feedback practice. The nature of such feedback also makes it transferable, in that its focus on the learning process extends beyond mere knowledge content and, indeed, the confines of a single assignment (Nicol 2010b, 513).

The students in the focus-group discussions also appreciated such constructive feedback. They viewed it as an important resource for their self-improvement.

Sometimes when you read the feedback, you're like, hey this makes sense-I shouldn't have made that error, but hey, I made that error [...] And hopefully I won't make the same error again. And there are other kinds of feedback, where you just didn't know that those kinds of error existed. You're like, huh, interesting. So in that case, I would probably talk to the tutor, and try to understand it better, because you know the second assignment usually has more weightage than the first assignment, so obviously you try to work on your second assignment [...] You try to use your first assignment's feedback to improve on the second assignment. (Samuel)

We see here an instance where the intention of the teacher and the subsequent action of the student match. The match, of course, cannot be perfect. The presumption is that such constructive feedback is informative enough for the student to understand the areas that require further work. But this need not always be so, as we shall see in Section 3.2 concerning the clarity of feedback. It is also unlikely for all students to respond to feedback in the same way. For instance, one student, Susan, stated that she would simply read the feedback and then return the assignment to her teacher. Her response, however, is in the minority. The other students indicated that they would take active steps to clarify doubts with their teachers. 
Facilitating such reflection and independent learning encourages interactivity between teachers and students. This is because teachers cannot claim to provide constructive feedback yet shy away from answering their students' queries. Naturally, making time to meet with students and address their queries outside class hours can be a problem for teachers with a heavy workload. For the teachers in this study, feedback-interaction time was incorporated as part of the curriculum - the students' assignments were returned during class, and the students were given adequate time to look over the feedback and raise any queries they might have. In the case of one teacher, Tricia, such interaction was so important that she would insist on individually meeting students who did badly in her assignments so that she could explain more fully the areas that needed improvement.

Notwithstanding the above, it needs to be noted that the feedback raised by both the teachers and students relates to comments on a completed assignment. Such end-ofassignment feedback, however, limits any help to the student only after, but not during, the writing of the assignment. Only one teacher pointed to the need for regular feedback to be provided. He noted:

It is based on my own experience in a writing course many years ago. I had to keep a writing journal and the tutor provided up to five times of feedback - no grades givenon different aspects of my writing each time (content and structure in particular) which I need to work on in order to perform in the final project [...] It was one of those courses that I felt the students were dealt with fairly; we were informed about our strengths and weaknesses progressively, given a chance to work on them, and attended to as learning individuals. (Timothy)

Apart from writing journals, an assignment system that requires students to first submit a draft version of their assignments can also help them to use the feedback on the drafts to craft an improved final version (Song, Lee, and Leong forthcoming). We will return to this issue regarding regular feedback in the concluding section of this paper.

\subsubsection{Grade justification}

The respondents' university uses a norm-referenced marking system, where the distribution of grades fits a bell curve. In view of the highly competitive environment at this university, students naturally take their grades seriously. In writing courses, the only way by which students can understand how well they have done in a particular assignment is to read their teacher's feedback. The student respondents agreed that, apart from the learning points for their self-improvement, they also frequently regarded the feedback as a justification of the grade they received, a collection of reasons as to why they performed the way they did. One student noted that the grade was essential to contextualize the feedback:

So the feedback can sound very harsh or it can sound very good, but once you see the grade, then you can contextualize that and say, okay, you know, my grade's an A-, but the feedback is harsh, so she's putting in the sense that okay, you could have gotten an A, but you failed to do this. (Steven)

Over time, this expectation led the teacher respondents to ensure that their feedback contained enough details to justify the grade assigned to the work. 
I have changed the way I give feedback, because you know, the students, they are so concerned about the grades. So I have learned from my colleagues, and from my own experience, to write more and more comments [...] to justify the grade that we give them. (Tammy)

For example, for a B- grade, I'll definitely put more comments. And definitely, I'll underline more language errors [...] (Titus)

The teachers' awareness of the importance of grade justification and the resulting effort to ensure that their feedback was not just constructive but explanatory highlight the adaptive nature of feedback. The teachers' willingness to accommodate their students' needs is to be commended, but it raises two concerns. The first, from the students' perspective, relates to an over-emphasis on grades. The students' focus on grades is understandable, since they determine the class of honors they graduate with, but any overemphasis may cause them to value the grade more than the feedback itself. As one of the teachers, Tracy, noted, obtaining good grades may become so important to students that they lose sight of the very purpose of learning.

The second relates to the context in which grade justification operates. Given the norm-referenced grading system of the university, it is inevitable that the grades of some students will have to be adjusted to fit the bell curve. (Such adjustments are not made known to the students.) When that happens, the original feedback may then need to be tailored-by introducing new comments or modifying the existing ones - to justify the new grades. This runs the risk of teachers providing feedback for self-preservation reasons, in the hope that the affected students (or others) will not raise any queries. There is no evidence from the focus-group discussions that such an issue poses a problem to the teacher respondents as it was never raised. For now, we view grade justification merely as a possible restriction on the nobler goal of helping students reflect, learn, and apply new skills. It should be stressed that there is no indication, at least from the focus-group discussions, that it is either pervasive or serious in the context of this study. There is also little that the teachers could have done to change the norm-referenced grading system of the university.

\subsection{Clarity of feedback}

A familiar refrain from the students in the discussion groups was the need for feedback to contain enough information for it to be helpful. The students noted that they would pay greater attention to the feedback if it was detailed, or at least specific about the problem or issue that they had to address. Seven of the eight students, for instance, preferred the clarity in the typewritten feedback as shown in Figure 2 (the sample was provided by a teacher at the Centre who was not involved as a respondent in the present study). The only exception was Steven, who expressed scepticism that writing teachers in general had the time (or energy) to produce such a report.

The feedback sample in Figure 2 is admittedly an exception rather than the norm among writing teachers. Notwithstanding this, the students' larger point about why they preferred it is noteworthy. 


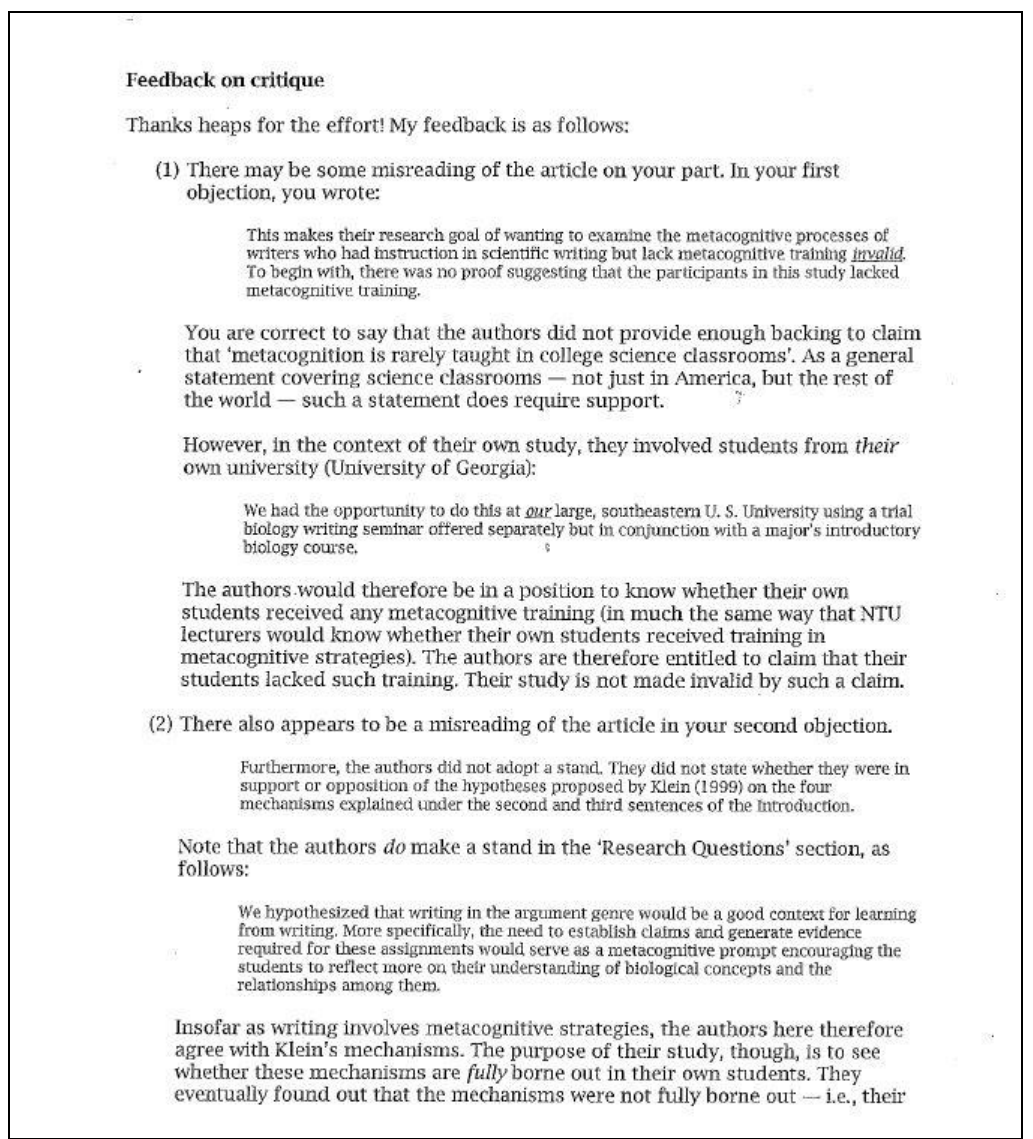

Fig. 2 Sample of detailed feedback preferred by students

[...] you can tell that the teacher put in a lot of effort. So some students who don't really like feedback, or are not very open to suggestions - I believe when I turn to the back and see that the teacher put in so much effort, I would want to read it. (Seth)

[...] this is great, because everything's organized-you can follow the flow properly. I think you would be encouraged to read. (Samuel)

Here, the students did not only value the clarity in the feedback, but they also appreciated the effort put in by the teacher. This highlights a potential factor, appreciation, that may influence how students respond to their teachers' feedback. This factor appears to rest on the students' implicit expectation of reciprocity, seen in terms of the effort put in by both themselves and the teacher - the former in crafting the assignment, and the latter, in providing clear, purposeful feedback. This is akin to students rationalizing "I've put in the effort; it would be nice if you did the same". From our conversations with the students, we further sensed that the teacher needs to be seen to be putting in this effort.

In practice, however, the students did not always receive feedback that was informative or even clear. They highlighted the need for more specific comments, with more elaboration 
and examples (Sharon, Susan, Samuel, Steven, Sabrina). Sharon, for instance, remarked that her teachers tended to "circle and comment, but we don't know what they mean". Another student, Sophia, found a particular comment on one of the feedback samples sarcastic. This comment_-"Did they?" - is located at the top right corner in Figure 3.

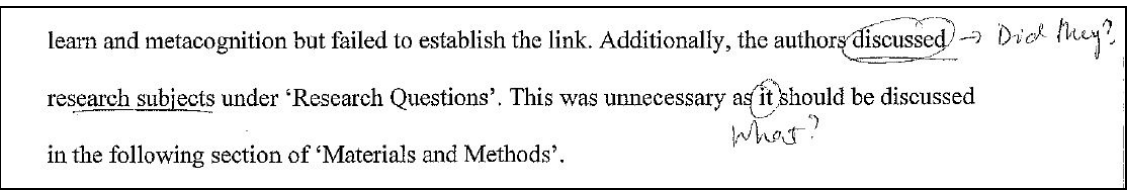

Fig. 3 Teacher's comment that Sophia found sarcastic

Sophia elaborated:

I really don't like it when they just circle something and put a question mark on top [...] Okay, it's wrong, but why is it wrong? And when the teacher writes "Did they?", I find that very sarcastic, you know. I'm a bit offended. The teacher could have just said "They didn't" or "No", instead of "Did they?". It's like the student didn't read properly.

Such sentiment is not uncommon among students elsewhere either. The literature on student perceptions of feedback reveals a general sense of dissatisfaction (e.g., Carless 2006). Students have been reported to find feedback being difficult to understand (Walker 2009), inadequate (Weaver 2006), and vague (Higgins, Hartley, and Skelton 2001). Walker's (2009) study, for instance, found that the most frequently occurring response from her student interviewees regarding feedback was "lack of understanding of comment and/or need for more explanation or detail". This finding is mirrored in the work of Weaver (2006), who found that the majority of her respondents agreed that their tutors did not provide enough feedback.

This, then, represents a challenge for teachers in providing indirect but constructive feedback. As we saw earlier, such feedback is generally welcomed by students, but in order for it to be useful, the feedback cannot be cryptic or vague. While this problem can certainly be minimized by encouraging students to raise any queries with the teacher, steps should be taken to avoid the problem as much as possible so that any feedback-interaction time can be better devoted to more pressing issues. There is no need, of course, for the feedback to resemble the sample in Figure 2, but the teacher could at least be mindful of the specific needs of each student and provide enough personalized pointers to help him or her perform better in subsequent tasks or assignments. We offer a few suggestions to achieve this in the concluding section.

\subsection{Specific areas of feedback}

We turn now to the third broad strand, on the specific areas addressed in teacher feedback. Among the teacher respondents, there was agreement that the areas addressed in the feedback depended primarily on the nature of the respective courses. Englishproficiency courses, for instance, laid emphasis on grammar and other language issues (e.g., cohesion, coherence). Courses on report writing, on the other hand, focused on rhetorical structure and argumentation. The teachers' feedback therefore addressed what was crucial to the requirements of the course. 
While this is a logical approach to the handling of feedback, it may not always meet the needs of students which are many and varied. The student respondents mentioned a range of areas that they would like their teachers' feedback to address. These included grammar (Seth, Samuel), argumentation (Sheldon), development of ideas (Susan, Sharon), and exemplars of good writing (Samuel, Steven). The issues ranged from specific (e.g., "vague questions marks" (Sabrina)) to broad concerns (e.g., "the big picture, the overall feel of the essay" (Steven)). This range of responses from the students is perhaps unsurprising, since different learners have different needs. Some of the student respondents who were proficient in the language (Steven) needed only comments on the broad direction of writing, whereas others who were less confident in their use of language (Susan, Sharon) required more detailed guidance.

The diverse concerns of the students highlight the need for personalized feedback to be used. We saw, in Section 3.1.2, how the teachers adapted to the expectations of their students regarding feedback as grade justification. This same adaptivity is needed here, where the specifics of feedback are concerned. Students are likely to perform better if the feedback is not just constructive, but personalized and responsive (Gallien and OomenEarly 2008, Plana-Erta, Moya, and Simo 2016). As one of the students pointed out:

If it's customised, then we can find out like, where our mistakes are. It's better! (Susan)

The provision of personalized feedback, while ideal, may be difficult for teachers with large classes and a heavy workload. Any interaction they may have with their students may also be perfunctory, resulting in feedback that addresses only the essential aspects of the assignment but not necessarily what the students need to better handle future assignments. We conclude our paper in the next section by addressing these concerns and providing some recommendations for feedback practice.

\section{CONCLUSION AND IMPLICATIONS FOR FEEDBACK PRACTICE}

Our study sought to investigate the views of both teachers and students regarding teacher feedback and feedback practice. We were interested in the areas where their perspectives matched and diverged. The focus-group discussions revealed the following key points:

(a) The teacher and student respondents agreed that feedback served the broad purpose of helping students to be reflective and independent learners. Any interaction between the teachers and students regarding feedback, however, revolved only around the completed assignment.

(b) While the students appreciated constructive feedback, they did not always receive feedback that was sufficiently informative.

(c) The teachers provided feedback that was closely aligned with the requirements of the respective courses. The individual, diverse needs of the students, however, were not always met.

The inputs of the teachers and students are summarized in Figure 4. As we have seen, there is general agreement between the teachers and students on the role of feedback in facilitating reflection and self-learning. Students are also afforded the opportunity to consult their respective teachers in class, or, as in the case of one teacher (Tricia), outside class. There is, however, a general consensus among the students that the feedback itself 
should be more detailed. Where the specific areas of feedback are concerned, there is much less agreement. The student respondents raised a number of issues that they would like their teachers' feedback to address, implying that this was not always done.

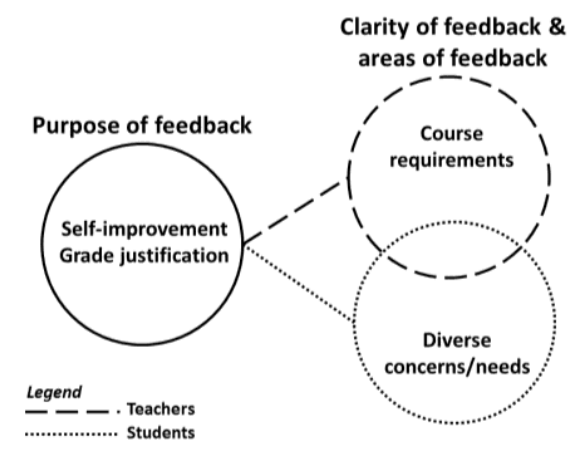

Fig. 4 Summary of respondents' inputs from focus-group discussions

This mismatch is likely brought about by the way student-teacher feedback interaction is manifested in practice. The feedback system appeared to focus on the product (i.e., the finished assignment) rather than the process of completing the product. The written feedback (as seen in Figures 1-2) and any time set aside for consultations revolved around the completed assignment. To create an environment where there is a fruitful exchange of ideas - and so increase the area of overlap between the dashed and dotted circles in Figure 4 , we propose the following recommendations.

\subsection{Revising the mode of assessment}

Courses at the Centre do not normally involve a writing-journal or draft-final mode of assessment, and so it is difficult to ascertain if the feedback truly helps students in subsequent tasks. Yet, introducing such modes of assessment enables students to incorporate constructive feedback in a purposeful way as they progress from their draft versions to the final ones. Feedback, seen in this light, has been aptly referred to in the literature as "feed forward" (Quinton and Smallbone 2010), and has been shown to result in improved student performance (Wimshurst and Manning 2013).

\subsection{Providing responsive and timely feedback}

In the event that time or institutional constraints do not allow for a writing-journal or draft-final mode of assessment, teachers can still provide adaptive, responsive feedback in at least two ways. The first is to use an interactive cover sheet (Bloxham and Campbell 2010) for students to indicate, prior to the submission of the assignment, the areas they prefer the feedback to address. A standardized form can be designed, with an open option for other concerns, to help students reflect more deeply about their current and desired levels. The teachers' feedback, in turn, becomes personalized and meets the needs of the students more directly. Importantly, the use of such forms can help to foster an environment where students take greater charge of their own learning. 
The second is to tap the learning technologies that are already available to the teachers and students. We have in mind learning-management systems (LMSs), such as Blackboard, which comprise a suite of resources (e.g., discussion board) that can be used by the teacher to keep track of the students' progress. Meeting students face-to-face is, of course ideal but it can be time consuming. One way around this constraint is the use of the discussion board in the university's LMS, where the teacher initiates questions, and provides timely feedback based on the students' inputs. This can go some way to motivate students and guide them in the learning process. Indeed, in an interesting study on online moderation, Packham et al. $(2006,245)$ found that students welcomed critical feedback in discussion forums and e-mail as they "enabled them to develop and enhance their contribution to the learning activity". The discussion board can be set up early in the semester so that students receive regular feedback throughout the assignment process. The teacher may wish to set aside a fixed time on a weekly (or even daily) basis to attend to his or her students' concerns. The asynchronous nature of the discussion board allows the teacher to reach out to students that he or she may not have been able to meet face-toface for one reason or another.

Incorporating these recommendations, we revise Figure 4 as Figure 5:

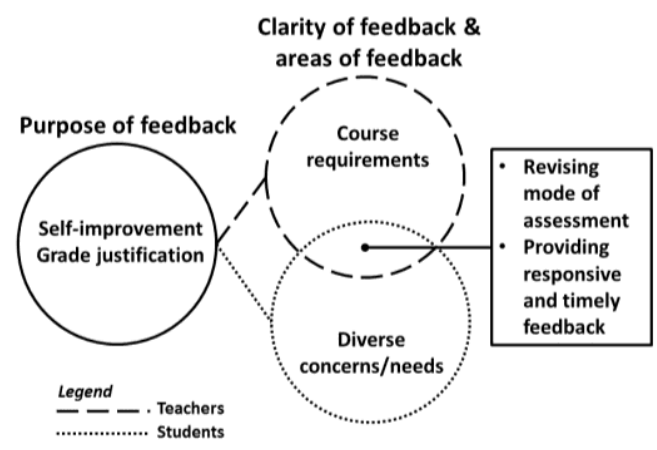

Fig. 5 Respondents' inputs from focus-group discussions and recommendations for feedback practice

As a concluding note, much more certainly needs to be done where such feedback research is concerned. This line of enquiry can be further extended to other disciplines and involve a greater number of participants. Studies of this nature, as our present work has shown, require the perspectives of both teachers and students to be considered so that areas that need attention can be addressed in an informed way. More crucially, perhaps, this study hopes to have drawn attention to the importance of action research, where teachers actively seek dialogue with their students to meet the writing and learning needs of the latter in specific contexts. The demand for personalized feedback will always be there. But it is through more interaction with students and, indeed, among teachers that innovative feedback strategies can be tested and implemented to enhance personalized learning in writing classrooms. 


\section{REFERENCES}

Bloxham, Sue, and Liz Campbell. 2010. "Generating dialogue in assessment feedback: Exploring the use of interactive cover sheets." Assessment \& Evaluation in Higher Education 35 (3):291-300. doi: 10.1080/02602931003650045.

Bruno, Inês, and Leonor Santos. 2010. "Written comments as a form of feedback." Studies in Educational Evaluation 36 (3):111-120. doi: 10.1016/j.stueduc.2010.12.001.

Carless, David. 2006. "Differing perceptions in the feedback process." Studies in Higher Education 31 (2):219-233. doi: 10.1080/03075070600572132.

Carless, David, Diane Salter, Min Yang, and Joy Lam. 2011. "Developing sustainable feedback practices." Studies in Higher Education 36 (4):395-407. doi: 10.1080/ 03075071003642449.

Ferris, Dana R. 2014. "Responding to student writing: Teachers' philosophies and practices." Assessing Writing 19:6-23. doi: 10.1016/j.asw.2013.09.004.

Gallien, Tara, and Jody Oomen-Early. 2008. "Personalized versus collective instructor feedback in the online courseroom: Does type of feedback affect student satisfaction, academic performance and perceived connectedness with the instructor?" International Journal on E-Learning 7 (3):463-476.

Glover, Ian, Helen J. Parkin, Stuart Hepplestone, Brian Irwin, and Helen Rodger. 2015. "Making connections: Technological interventions to support students in using, and tutors in creating, assessment feedback." Research in Learning Technology 23:27078. doi: 10.3402/rlt.v23.27078.

Hattie, John A., and Helen Timperley. 2007. "The power of feedback." Review of Educational Research 77 (1):81-112. doi: 10.3102/003465430298487.

Higgins, Richard, Peter Hartley, and Alan Skelton. 2001. "Getting the message across: The problem of communicating assessment feedback." Teaching in Higher Education 6 (2):269-274. doi: 10.1080/13562510120045230.

Hyland, Ken. 2013a. "Faculty feedback: Perceptions and practices in L2 disciplinary writing." Journal of Second Language Writing 22:240-253. doi: 10.1016/j.jslw.2013.03.003.

Hyland, Ken. 2013b. "Student perceptions of hidden messages in teacher written feedback." Studies in Educational Evaluation 39:180-187. doi: 10.1016/j.stueduc.2013.06.003.

Laurillard, Diana. 2002. Rethinking University Teaching: A Framework for the Effective Use of Learning Technologies. 2nd ed. London: Routledge.

Lee, Hwee Hoon, Ping Alvin Leong, and Geraldine Song. 2017. "Investigating teacher perceptions of feedback." ELT Journal 71 (1):60-68. doi: 10.1093/elt/ccw047.

Lee, Icy. 2008. 'Understanding teachers' written feedback practices in Hong Kong secondary classrooms." Journal of Second Language Writing 17 (2):69-85. doi: 10.1016/j.jslw. 2007.10.001.

Lee, Icy. 2009. "Ten mismatches between teachers' beliefs and written feedback practice." ELT Journal 63 (1):13-22. doi: 10.1093/elt/ccn010 13.

Mahboob, Ahmar. 2015. 'Understanding and providing 'cohesive' and 'coherent' feedback on writing." Writing \& Pedagogy 7 (2-3):401-422. doi: 10.1558/wap.v7i2-3.26461.

Mutch, Allyson, Charlotte Young, Tamzyn Davey, and Lisa Fitzgerald. forthcoming. "A journey towards sustainable feedback." Assessment \& Evaluation in Higher Education: 112. doi: 10.1080/02602938.2017.1332154. 
Nicol, David J. 2010a. "From monologue to dialogue: Improving written feedback processes in mass higher education." Assessment \& Evaluation in Higher Education 35 (5):501-517. doi: 10.1080/02602931003786559.

Nicol, David J. 2010b. "From monologue to dialogue: Imprving written feedback in mass higher education." Assessment \& Evaluation in Higher Education 35 (3):501-517. doi: $10.1080 / 02602931003786559$.

Nicol, David J., and Debra Macfarlane-Dick. 2006. "Formative assessment and selfregulated learning: A model and seven principles of good feedback practice." Studies in Higher Education 31 (2):199-218. doi: 10.1080/03075070600572090.

O’Donovan, Berry, Chris Rust, and Margaret Price. 2016. "A scholarly approach to solving the feedback dilemma in practice." Assessment \& Evaluation in Higher Education 41 (6):938-949. doi: 10.1080/02602938.2015.1052774.

Orsmond, Paul, Stephen J. Maw, Julian R. Park, Stephen Gomez, and Anne C. Crook. 2013. "Moving feedback forward: Theory to practice." Assessment \& Evaluation in Higher Education 38 (2):240-252. doi: 10.1080/02602938.2011.625472.

Packham, Gary, Paul Jones, Brychan Thomas, and Christopher Miller. 2006. "Student and tutor perspectives of on-line moderation." Education + Training 48 (4):241-251. doi: 10.1108/00400910610671915.

Pitt, Edd, and Lin Norton. 2017. “'Now that's the feedback I want!' Students' reactions to feedback on graded work and what they do with it." Assessment \& Evaluation in Higher Education 42 (4):499-516. doi: 10.1080/02602938.2016.1142500.

Plana-Erta, Dolors, Soledad Moya, and Pep Simo. 2016. "The effectiveness of instructor personalized and formative feedback provided by instructor in an online setting: Some unresolved issues." Electronic Journal of E-Learning 14 (3):196-203.

Price, Margaret, Karen Handley, Jill Millar, and Berry O'Donovan. 2010. "Feedback: All that effort, but what is the effect?" Assessment \& Evaluation in Higher Education 35 (3):277-289. doi: 10.1080/02602930903541007.

Quinton, Sarah, and Teresa Smallbone. 2010. "Feeding forward: Using feedback to promote student reflection and learning - a teaching model." Innovations in Education and Teaching International 47 (1):125-135. doi: 10.1080/14703290903525911.

Song, Geraldine, Hwee Hoon Lee, and Ping Alvin Leong. forthcoming. "Students' response to feedback: An exploratory study." RELC Journal. doi: 10.1177/0033688217691445.

Stern, Lesa A, and Amanda Solomon. 2006. "Effective faculty feedback: The road less traveled." Assessing Writing 11 (1):22-41. doi: 10.1016/j.asw.2005.12.001.

Walker, Mirabelle. 2009. "An investigation into written comments on assignments: do students find them usable?" Assessment \& Evaluation in Higher Education 34 (1):6778. doi: 10.1080/02602930801895752.

Weaver, Melanie R. 2006. "Do students value feedback? Student perceptions of tutors' written responses." Assessment \& Evaluation in Higher Education 31 (3):379-394. doi: 10.1080/02602930500353061.

Wimshurst, Kerry, and Matthew Manning. 2013. "Feed-forward assessment, exemplars and peer marking: Evidence of efficacy." Assessment \& Evaluation in Higher Education 38 (4):451-465. doi: 10.1080/02602938.2011.646236. 